\title{
Atypic separator gel flotation in blood collection tube in a patient with hyperproteinemia
}

\author{
Nesibe Esra Yasar'1, (D) Dildar Konukoglu²
}

'Department of Medical Biochemistry, Ministry of Health, Kars Harakani Public Hospital, Kars, Turkey

${ }^{2}$ Department of Medical Biochemistry, Istanbul Univesity-Cerrahpasa, Faculty of Medicine, Istanbul, Turkey

\begin{abstract}
Serum separator gel tubes are widely used in laboratories for blood collection since their advantages. These contain a gel that forms a barrier between serum and clot after centrifugation. Rarely, some conditions may arise from unusual separation patterns. In this case, the floating separator gel due to hyperproteinemia was reported. A 49-yearold woman admitted to the chest diseases department. The blood sample was collected into a gel separation tube, transported to the Medical Biochemistry Laboratory within 45 minutes and centrifuged at $1500 \mathrm{~g}$ for 10 minutes. The separator gel formed the topmost layer, with the serum in the middle and the clot at the bottom. The sample was recentrifuged, but this atypical phenomenon did not change. The serum was aspirated under the gel layer by a pipette. Biochemical analyses showed markedly elevated total protein concentration ( $147 \mathrm{~g} / \mathrm{L})$. The patient's file revealed that she had no history of chronic disease other than chronic obstructive pulmonary disease. When consulted, the clinician informed us that the patient was directed for further examination because of the high total protein levels. Laboratories should be careful of the limitation of gel separation tubes. In addition, all samples must be visually checked before analysis, as an aspiration of misplaced gel may obstruct the analyzer probes; causing technical problems, time loss, adverse patient outcome, and extra cost.
\end{abstract}

Keywords: Blood collection tube, floating gel, hyperproteinemia, preanalytical phase

S erum blood collection tubes with separator gel are wideSly used in laboratories for blood collection today. These tubes have some advantages, such as improvement of serum stability, enable to the higher amount of serum, decreased sample manipulations, and minimize aerosolization of hazardous substances. The use of serum separator gel tubes for sample collection enables their use for also sample storage as a secondary tube. Thus, there is no need to re-barcode the tubes, and the possibility of sample switching is reduced [1].

Serum separator gel tubes contain an inert, thixotropic polymer gel which has a density between that of serum and clot. Hence, a barrier consists of between the liquid and the cellular components after centrifugation that prevents the mixing of substances originated from cells to the serum [2]. Rarely, in some conditions that increase the density of serum-like hyper- proteinemia [3], spurious hypernatremia [4], or administration of contrast media [5] may be caused by unusual separation patterns. In this study, we reported a case of floating separator gel due to hyperproteinemia.

\section{Case Report}

A 49-year-old woman with chronic obstructive pulmonary disease admitted to the chest diseases department. Blood sample was collected into a gel separation tube (Greiner Bio-One Vacuette) and transported to the Medical Biochemistry Laboratory of Kars Harakani Public Hospital within 45 minutes. When the sample was centrifuged at $1500 \mathrm{~g}$ for 10 minutes, it was observed that the separator gel formed the topmost layer, with the serum in the middle and the clot at

Address for correspondence: Nesibe Esra Yasar, MD. Department of Medical Biochemistry, Ministry of Health, Kars Harakani Public Hospital, Kars, Turkey Phone: +90 5534617049 E-mail: esrayasar2014@hotmail.com ORCID: 0000-0002-5744-5735

Submitted Date: July 24, 2020 Accepted Date: August 06, 2020 Available Online Date: October 06, 2020

${ }^{\circ}$ Copyright 2020 by International Journal of Medical Biochemistry - Available online at www.internationalbiochemistry.com

OPEN ACCESS This work is licensed under a Creative Commons Attribution-NonCommercial 4.0 International License. 
the bottom (Fig. 1). The sample was re-centrifuged, but this atypical phenomenon did not change. This abnormal gel flotation suggested that the density of the serum may be higher than the gel layer. The appearance of the serum was not hemolytic, lipemic or icteric. The serum was aspirated under the gel layer by a pipette, and biochemical analyses were performed by an auto-analyzer (Roche Diagnostics, Cobas c501, Tokyo, Japan). The results confirmed by re-analysis showed that the total protein concentration markedly elevated ( $147 \mathrm{~g} / \mathrm{L}$; reference interval: 66-87) and the albumin (25 g/L; reference interval: 35-52) and sodium (131 mmol/L; reference interval: 135-145) levels were decreased. The patient's file revealed that she has no history of chronic disease other than chronic obstructive pulmonary disease. However, high total protein and low albumin concentrations were obtained in the biochemical analysis at the previous hospital

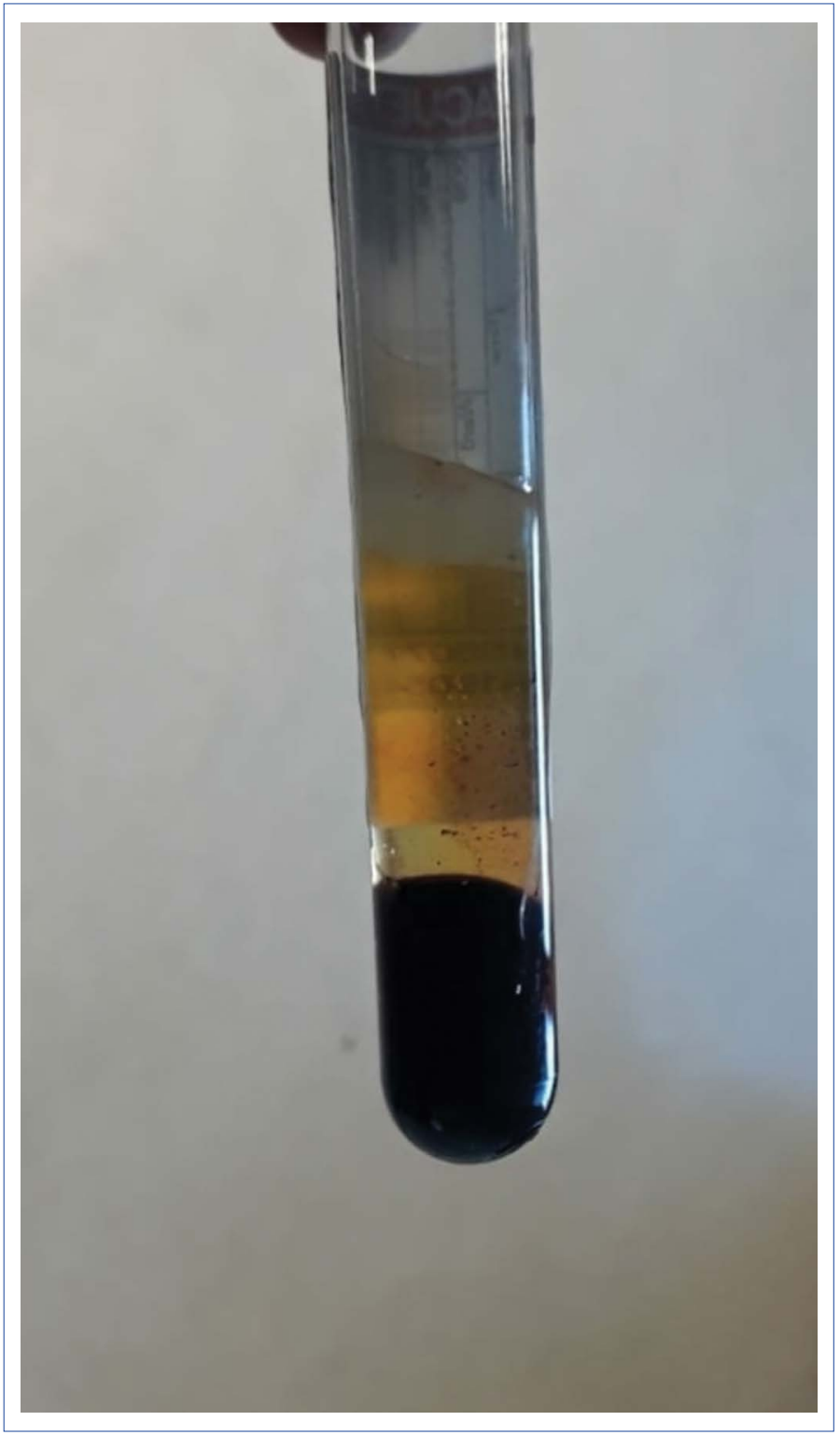

Figure 1. Abnormal floating separator gel after centrifugation. administrations. A few samples taken from the patient into the gel separation tube were also rejected previously because of unsuitable for the analysis, and the biochemistry tests were not performed.

One week later, she presented to the emergency department with chest pain. The blood sample was collected into a gel separation tube (Greiner Bio-One Vacuette) for the routine biochemistry and cardiac marker analysis. The sample arrived at Stat Laboratory of Kars Harakani Public Hospital within only nine minutes and centrifuged at $1500 \mathrm{~g}$ for 10 minutes. Contrary to expectations, the serum formed the upmost layer was separated from the cells by the gel. In routine biochemistry analysis, the high total protein $(142 \mathrm{~g} / \mathrm{L})$ and low albumin $(18.3 \mathrm{~g} / \mathrm{L})$ and sodium $(133 \mathrm{mmol} / \mathrm{L})$ concentration were detected once again. The patient's consent was obtained for this study.

\section{Discussion}

Many laboratories perform routine biochemistry analyzes in blood samples collected in serum separator gel tubes. The liquid and cellular components of the blood have a density between 1.026 to $1.031 \mathrm{~g} / \mathrm{cm}^{3}$ and 1.092 to $1.095 \mathrm{~g} /$ $\mathrm{cm}^{3}$, respectively [2]. Although separator gel density varies between tubes from different manufacturers, it ranges between 1003 and $1009 \mathrm{~g} / \mathrm{cm}^{3}$, which permit its suitable positioning between liquid and cellular components of blood after centrifugation [2]. The position of the gel is influenced by many variables like tube factors (specific gravity, yield stress, viscosity, density, and tube material), laboratory conditions (centrifugation speed, temperature, acceleration and deceleration and, storage conditions) and patient characteristics (heparin therapy, low hematocrit, elevated plasma protein, contamination of the sample with contrast media or catheter locking solution) [6]. The improper positioning of the gel can be the cause of several technical and clinical problems when not detected. The analyzer probes may be partially or completely obstructed by the gel. Thus, they compromise the effective and reliable working of the device. The aspiration of gel along with the sample may also spuriously modify the test results, falsely low or high test results adverse effect on patient outcome.

In previous studies, it has been shown that abnormal gel formation may occur in diseases with hyperproteinemia, such as multiple myeloma and related disorders. van den Ouweland et al. [7] observed that the autoanalyzer probe occluded due to the aspiration of the separator gel in samples collected from two patients diagnosed with multiple myeloma. When the blood samples collected in plain tubes, it was reported that the total protein levels were markedly elevated in both patients. Chakraborty et al. [8] examined the 42,080 blood samples collected in serum separator tubes during the 2-year study period. They reported that in 16 of 23 samples showing improper gel separation, this unusual phenomenon is associated with monoclonal gammopathy. Demir et al. [3] reported 
abnormal gel flotation due to hyperproteinemia in three patients with hemodialysis.

Paraproteinemia may also interfere in some clinical chemistry measurements by many mechanisms. Increasing serum or plasma viscosity due to elevated protein concentration may cause a relative decrease in liquid compartments, leading to false-negative quantification amounts of other solute molecules [9]. The decreased sodium levels, in this case, can be explained by this mechanism. The precipitation of paraproteins with reagents increase the sample turbidity and lead to interference in nephelometric, turbidimetric or colorimetric analysis. Paraproteins also may interfere immunoassays by interaction with the specific antibody reagents [10]. Another mechanism is that paraproteins inhibit of three stages of fibrin formation: the proteolytic action of thrombin on fibrinogen, the aggregation of fibrin monomers, and the stabilization of fibrin by cross-linkages in the $\gamma$ and a chain. Residual fibrin masses may cause bulky gelatinous clot formation and make it difficult to separate the serum after centrifugation [10]. Thus, obtaining sufficient serum for biochemical analyses becomes difficult. In addition, technical problems may occur with the obstruction of autoanalyzer probes, partially or completely. Improper amount of sample aspiration, along with the fibrin clots, may also spuriously modify the test results.

In this case, when the sample was kept for a short time, the serum was separated normally although the high total protein concentration. Waiting for the sample for a long time may increase the precipitation of paraproteins, making it difficult to separate the serum. This patient was consulted with the clinician for high total protein concentration, abnormally serum separation, and interferences of paraproteinemia. The patient's physician informed us that the patient was directed for further examination because of the high total protein levels. We also suggested to the clinic to take blood to the plain tube for laboratory tests during the patient's follow-up and to transport to the laboratory as soon as possible.

\section{Conclusion}

Laboratories should be careful of the limitation of using the gel separator tubes in patients with high total protein concentrations. In these cases, blood samples should be collected in non-separator tubes and analyzed in a short time. In addition, all samples must be visually checked before analysis, as an aspiration of misplaced gel can obstruct the analyzer probes, causing technical problems, time loss, adverse patient outcome, and extra cost.

Informed Consent: The informed constent was obtained.

Conflict of Interest: None declared.

Financial Disclosure: This research did not receive any specific grant.

Peer-review: Externally peer-reviewed.

Authorship Contributions: Concept - N.E.Y., D.K.; Design N.E.Y., D.K.; Supervision - N.E.Y., D.K.; Funding - None; Materials - N.E.Y.; Data collection \&/or processing - N.E.Y.; Analysis and/or interpretation - N.E.Y.; Literature search - N.E.Y.; Writing - N.E.Y., D.K.; Critical review - N.E.Y., D.K.

\section{References}

1. Bowen RA, Remaley AT. Interferences from blood collection tube components on clinical chemistry assays. Biochem Med (Zagreb) 2014;24(1):31-44.

2. Fatás $M$, Franquelo $P$, Franquelo R. Anomalous flotation of separator gel: density or viscosity? Clin Chem 2008;54(4):771-2.

3. Demir M, Ozdem S, Sarier M. Abnormal Flotation of Separator Gel in Blood Test Tubes in the Hemodialysis Patients. EJMI 2019;3(4):280-4.

4. Srivastava R, Murphy MJ, Card J, Severn A, Fraser CG. The case of the floating gel. J Clin Pathol 2004;57(12):1333-4.

5. Daves M, Lippi G, Cosio G, Raffagnini A, Peer E, Dangella A, et al. An unusual case of a primary blood collection tube with floating separator gel. J Clin Lab Anal 2012;26(4):246-7.

6. Bowen RA, Hortin GL, Csako G, Otañez OH, Remaley AT. Impact of blood collection devices on clinical chemistry assays. Clin Biochem 2010;43(1-2):4-25.

7. van den Ouweland JM, Church S. High total protein impairs appropriate gel barrier formation in BD Vacutainer blood collection tubes. Clin Chem 2007;53(3):364-5.

8. Chakraborty S, Chowdhury SR, Krishnan P, Sanyal S, Bhattacharya $C$, Sen S. Improper serum separation on gel tubes: a trivial laboratory problem or an indicator of monoclonal gammopathy? Clin Chem Lab Med 2014;52(12):e275-8.

9. Piyophirapong S, Wongtiraporn W, Sribhen K. Factitious Results in Clinical Chemistry Tests Caused by Common Endogenous Interferents. Siriraj Med J 2010;62:185-8.

10. Pallavi $B$, Krishnamurthy $U$. An unique encounter with paraprotenemia. J Lab Physicians 2019;11:391-3. 